\title{
Prophylactic Use of Haloperidol versus Atypical Antipsychotics (Quetiapine) in Prophylaxis Against ICU Delirium in High Risk Patients
}

\author{
ELHAM A. SIAM, M.D.; SANAA M. AL-FAWAL, M.D.; ISLAM A. TAHER, M.D. and \\ HEBA A. ELKHAIR, M.Sc.
}

The Department of Anesthesia, Intensive Care and Pain Management, Faculty of Medicine, Ain Shams University

\begin{abstract}
Background: The prevalence of delirium reported in medical and surgical ICU has varied from $20 \%$ to $80 \%$, depending upon severity of illness observed and diagnostic methods used.

Aim of Study: To examine the efficacy and safety of Quetiapine in the prophylaxis against delirium in high risk critically ill patient and comparing its effect with haloperidol.

Patients and Methods: This study was conducted on a total of 70 adult, conscious patients, who were admitted to Critical Care Medicine Department of El-Demerdash Hospital, Shebein Elkom Teaching Hospital. Patients were categorized into two groups using conventional method of randomization from the day of admission: Group I for high risk patient whom received $0.5-1.5 \mathrm{mg} / \mathrm{day}$ haloperidol for prophylaxis of delirium till onset of delirium, acute attack resolved and ICU discharge. Group II for high risk patient whom received $25-75 \mathrm{mg} /$ day Quetiapine for prophylaxis of delirium till onset of delirium, acute attack resolved and ICU discharge.
\end{abstract}

Results: Frequent assessment of both groups at $12 \mathrm{hrs}$ interval for the onset of delirium by using CAM-ICU score revealed significantly lower incidence of delirium in group II $(17.1 \%)$ than in group I (40\%), $p=0.034$. Further, all survived patients in both groups showed negative CAM score at the time of discharge. Monitoring the occurrence of side effects in both groups showed significantly greater incidence of extrapyramidal effects, prolonged QT and hypotension in group I $(2.9 \%, 8.6 \%, 14.3 \%$ respectively) compared to group II $(0.0 \%, 0.0 \%, 2.9 \%$ respectively $)(p=0.032)$.

Conclusion: This study reflects the advantage of using Qutepiene as a newer antidelrium therapy over Halopredol as a prophylaxis against ICU delirium in high risk patients. Qutiepiene, compared to Haloperidol is less in developing serious side effect e.g. prolonged QT interval, extrapyramidal manifestations and hypotension.

Key Words: Haloperidol-Atypical Antipsychotics (Quetiapine) - Prophylaxis - ICU Delirium - High risk patients.

Correspondence to: Dr. Heba A. Elkhair, E-Mail: heba.aly4848@ gmail.com

\section{Introduction}

DELIRIUM is defined as acute brain dysfunction featured by disturbances of attention, awareness and cognition with a fluctuating course caused by an underlying medical condition [1], occurs frequently in the intensive care unit, is associated with impaired patient outcome, and substantially increases healthcare costs. Given these deleterious consequences, delirium prevention is crucial [2] .

Multiple factors contribute to the development of delirium, including preexisting cognitive dysfunction, alcohol, drug withdrawal, sedative use, inadequate sleep, painful procedures, infection and shock state [3].

Delirium preventive measures are important for all ICU patients. However a delirium prediction model may facilitate early recognition of the patients who may benefit the most from delirium prevention. Non pharmacologic reduction strategies and medication-based strategies may be most relevant for patients who have an increased risk of developing delirium [4].

Halopridol is a typical antipsychotic medication. Halopridol is used in the treatment of schizophrenia, mania in bibolar disorder, delirium, agitation, acute psychosis and hallucinations in alcohol withdrawal. Despite limitations due to adverse events, including QT prolongation with the potential to trigger ventricular tachycardia, hypotension and extrapyramidal side effects [5]

Quetiapine is an atypical antipsychotic drug used in treating schizophrenia, mania, depression and acute delirium outside the ICU [6] . 
Quetiapine has few extrapyramidal side effects or anticholinergic symptoms, a short half-life and is mildly sedating [7].

\section{Aim of the work:}

The aim of study is to compare the efficacy and safety of Quetiapine in prophylaxis against ICU delirium in high risk patient with that of haloperidol.

\section{Patients and Methods}

This study was conducted on adult, conscious patients, who were admitted to Critical Care Medicine Department of Al-Demerdash Hospital, Shebin Alkom Teaching Hospital during 2020 after obtaining approval of the study protocol from the local ethical committee, as well as fully informed written consents signed by the patients' closet relatives, 70 patients admitted at ICU, high risk for delirium.

The aim of the study was explained to the caregivers, the caregivers were told about the available pharmacotherapy for prophylaxis of delirium, they were told about efficacy and side effects profile of the drugs, they were informed that they could withdraw consent at any stage.

Patients were randomly selected, using sealed envelopes, only those who fulfilled criteria of high risk for developing delirium (based on Diagnostic and statistical manual, 4 th revision) and were aged more than 21 yrs were included into the study and divided into two equal groups using flexible dosing regimen: Group 1 included 35 patients assigned to receive Halopreridol and group 2 included 35 patients assigned to receive Quetiapine.

Methods:

A- All patients who were admitted to Critical Care Medicine Department were subjected to the following on admission:

1- History included personal data: Name, age, and gender, past history of chronic diseases; DM, cardiac, pulmonary neurological, psychological, renal and hepatic disease, drug history including sedation, Alcohol intake and opioid, duration of hospital and ICU stay, cause and duration of mechanical ventilation if patient is ventilated and previous attack of delirium.

2- Clinical examination: Physical examination was done (cardiac, chest, abdominal, neurological) and vital sign included blood pressure, heart rate and rhythm, temperature and respiratory rate.
3- Laboratory evaluation included complete blood count was done daily, renal function tests, Liver function tests, Electrolyte profile will be done every 3 days weekly, random blood sugar was done daily and arterial blood gases were done on demand.

\section{B- APACHE score:}

Using APACH II score to detect the severity of illness which included in increasing risk for developing delirium.

The Acute physiology and chronic health evaluation II (APACHE II) was assessed for all patients of both groups as abaseline score on 1 day of admission in ICU, as higher APACHE II score increase incidence of occurrence of delirium.

APACHE II score was assessed for all patients of both groups on day of discharge also.

\section{C-. RASS score:}

Accepted score is 0 as the patient is alert and calm. $+1:+4$ denotes hyperactive delirium during all assessments. -1: -3 denotes hypoactive delirium during all assessments. +4:-3 denotes mixed delirium which is characterized by alternating symptoms of hyperactive and hypoactive delirium. If it ranges between -3 to +4 proceed to CAM-ICU score. If RASS is -4 or -5 stop (patient is unconscious), recheck later.

Assessment of RASS score was done for all patients of both groups every 12 hours daily till patient was CAM-ICU positive or negative for delirium and continue till delirium resolved and patient discharged.

\section{D- CAM-ICU score:}

Confusion Assessment Method (CAM-ICU) was applied on all patients daily in ICU from 1 st day of admission.

On 1 st day of admission CAM-ICU score was negative for both groups.

Regular monitoring every 12 hour daily for patients of both groups till score considered positive.

Patients were diagnosed with delirium when they had at least one positive CAM-ICU screening during their complete ICU stay. A delirium-andcoma-free day was defined as a negative CAMICU screening without RASS -4/-5 during a complete day. 
It detects four features of delirium: Acute onset of mental status changes or a fluctuating course; inattention; disorganized thinking; and altered level of consciousness. To have delirium diagnosed, a patient must display the first two aforementioned features, with either the third or fourth aforementioned feature.

Assessment with CAM-ICU score continued every 12 hour daily till all discharged patients of both groups are negative for delirium.

\section{Dosing of study medications:}

The dose of medication was adjusted according to clinical judgement, using flexible dosing regimen (haloperidol $0.5-1.5 \mathrm{mg}$ daily and quetiapine $25-$ $75 \mathrm{md}$ daily) in concurrent with non pharmacological methods for preventing delirium.

Based on the daily clinical assessment, we started with the least dose used as a prophylaxis of delirium. If delirium occur as a primary outcome, We increased the dose, but not exceeding dosing regimen. The secondary outcome was improving of the patient and discharge from ICU.

\section{E- Routine evaluation to detect the side effect of} two administrated drug through daily:

- ECG was done as a baseline tool on day of admission for each patient of both groups, any patient with prolonged QT interval was excluded from the study.

- ECG was done daily for all patients of both groups along their stay in ICU, along their administration of medication till their discharge from ICU.

- Routine monitoring of Vital signs for all patients of both groups regularly in ICU.

- If patient developed hypotension (Hypotension was defined as systolic blood pressure decrease of more than $20 \%$ from base line), adjust study drug dose with concurrent correction of general condition of patient by intravenous bolus fluids or by vasoactive drugs cautiously according to the patient state.

- Daily assessment of Extrapyramidal manifestations using Simpson-angus scale from ${ }^{\text {st }}$ dose of Halopridol, Quetiapine till occurrence of side effects or discharge from ICU without complications.

- If patient developed EPS, stop medication and follow-up.

\section{Statistical analysis:}

Sample size was done using STATA program, setting alpha error study at $5 \%$ \& power at $80 \%$ result from previous study Boogard et al. (2013) showed that the incidence of delirium in halopredol group was $65 \%$, while its assumed to be $30 \%$ in quetiapine group. Based on this, the needed samples were 35 cases per group (70 Total).

Statistical analysis and presentation of data was conducted using SPSS (Statistical Package for the Social sciences) version 22 computer program.

Categorical data were presented as numbers and percentages and were analyzed by using ChiSquare or Fisher's Exact tests as appropriate. Continuous numerical data were tested for normality by Shapiro Wilk test.

Normally distributed data were expressed as mean \pm standard deviation and were compared by using Independent $t$-test.

Whereas, not normally distributed data were expressed as median and interquartile range (expressed as 25 th-75 th percentiles) and were analyzed by Mann-Whitney U test. $p<0.05$ was considered statistically significant.

\section{Results}

Table (1) shows a comparable distribution of sex between the studied groups with no significant difference $(p=0.089)$. Whereas, the median age of patients in group I 61.0 (IQR=53.0-67.0) was significantly higher than in group II 52.0 (IQR= 32.0-64.0), $p=0.012$.

Table (1): Demographic data of the studied groups.

\begin{tabular}{|c|c|c|c|c|}
\hline & \multicolumn{2}{|c|}{ Groups } & \multirow{2}{*}{$\begin{array}{c}\text { Test } \\
\text { statistic }\end{array}$} & \multirow{2}{*}{$\begin{array}{c}p- \\
\text { value }\end{array}$} \\
\hline & $\begin{array}{l}\text { Group } 1 \\
\mathrm{~N}=35\end{array}$ & $\begin{array}{c}\text { Group } 2 \\
\mathrm{~N}=35\end{array}$ & & \\
\hline \multicolumn{5}{|l|}{ Sex: } \\
\hline \multicolumn{5}{|l|}{ Female: } \\
\hline $\mathrm{N}$ & 11 & 18 & 2.885 & 0.089 \\
\hline$\%$ & $31.4 \%$ & $51.4 \%$ & & \\
\hline \multicolumn{5}{|l|}{ Male: } \\
\hline $\mathrm{N}$ & 24 & 17 & & \\
\hline$\%$ & $68.6 \%$ & $48.6 \%$ & & \\
\hline \multicolumn{5}{|l|}{ Age (years): } \\
\hline $\begin{array}{l}\text { Minimum - } \\
\text { Maximum }\end{array}$ & $18.0-70.0$ & $23.0-69.0$ & 2.51 & $0.012 *$ \\
\hline Median (IQR) & $\begin{array}{l}61.0 \\
(53.0-67.0)\end{array}$ & $\begin{array}{l}52.0 \\
(32.0-64.0)\end{array}$ & & \\
\hline Mean rank & 41.60 & 29.40 & & \\
\hline
\end{tabular}

*Significant at $p<0.05$. IQR: Interquartile range.

Most of patients in groups I and II showed high frequency of combined comorbidities including diabetes, hypertension, cardiac, and hepatic diseases (48.6\% and $51.4 \%$ respectively) with no significant 
differences ( $p=0.409)$. Furthermore, all patients gave no reported history of alcohol abuse or opiates abuse in both groups as demonstrated in Table (2).

Table (2): Comorbid conditions and drug abuse history.

\begin{tabular}{llllllll}
\hline & \multicolumn{9}{c}{ Groups } & & \\
\cline { 2 - 5 } & $\begin{array}{c}\text { Group 1 } \\
\text { N=35 }\end{array}$ & $\begin{array}{c}\text { Group 2 } \\
\text { N=35 }\end{array}$ & $\begin{array}{c}\text { Test } \\
\text { statistic value }\end{array}$ & $\begin{array}{c}p \text { - } \\
\end{array}$ \\
\cline { 2 - 5 } & $\mathrm{N}$ & $\%$ & $\mathrm{~N}$ & $\%$ & & \\
\hline Comorbid conditions: & & & & & & \\
DM & 6 & 17.1 & 5 & 14.3 & 5.123 & 0.409 \\
Hepatic & 4 & 11.4 & 2 & 5.7 & & \\
Cardiac & 3 & 8.6 & 0 & 0.0 & & \\
Hypertension & 1 & 2.9 & 2 & 5.7 & & \\
Combined & 17 & 48.6 & 18 & 51.4 & & \\
Others & 4 & 11.4 & 8 & 22.9 & & \\
Alcohol abuse: & & & & & & \\
$\quad$ No & 35 & 100.0 & 35 & 100.0 & - & - \\
Opiates abuse: & & & & & & \\
$\quad$ No & 35 & 100 & 35 & 100.0 & - & - \\
No & 0 & 0.0 & 0 & 0.0 & & \\
\hline
\end{tabular}

Comparison of severity assessed by APACHEII score between the studied groups was illustrated in Table (3). The mean APACHE II score on admission was significantly higher in group I ( $21 \pm 4.3)$ than group II $(18.1 \pm 5.2)$. Two patients were died each in group I and group II. Assessment of severity at discharge revealed significantly higher mean APACHE II score in group I (12.9 \pm 3.3$)$ than group II $(9.7 \pm 2.6)$.

Table (3): Severity assessed by APACH II score of the studied groups.

\begin{tabular}{lllll}
\hline & \multicolumn{2}{c}{ Groups } & Test & $p$ - \\
\cline { 2 - 3 } & $\begin{array}{c}\text { Group 1 } \\
\mathrm{N}=35\end{array}$ & $\begin{array}{c}\text { Group 2 } \\
\mathrm{N}=35\end{array}$ & statistic & value \\
\hline APACH II & & & & \\
on admission: & & & & \\
Mini- Maxi & $9.0-30.0$ & $9-26$ & 2.690 & $<0.017^{*}$ \\
Mean & 21 & 18.1 & & \\
SD & 4.3 & 5.2 & & \\
APACHEII & & & & \\
on discharge: & & & & \\
Mini- Maxi & $9.0-22$ & $6-15$ & 5.665 & $<0.001^{*}$ \\
Mean & 12.9 & 9.7 & & \\
SD & 3.3 & 2.6 & & \\
*Significant at $p<0.05$. & \multicolumn{3}{c}{ IQR: Interquartile range. } \\
Mini- Maxi: Minimum- Maximum. & SD : Standard deviation
\end{tabular}

Table (4) demonstrates that RASS score was 0 in both groups on day of admission, all patients were alert and calm.

RASS score ranged from -1 to +3 in group 1 and from 0 to +2 in group 2 on the day of onset of delirium. There were significant differences be- tween the studied groups as regards the frequency of different grades of agitation or sedation as assessed by RASS score on the day of onset of delirium $(p=0.035)$. On the day of the onset of delirium, agitated patients (grades $+1,+2$ and +3 ) represented $20 \%, 8.57 \%, 2.9 \%$ in group I compared to $14.3 \%, 8.57 \%, 0.0 \%$ in group II.

Finally, all survived patients were alert and calm on discharge in both groups.

Table (4): Assessment of RASS score in the studied groups.

\begin{tabular}{|c|c|c|c|c|c|c|}
\hline \multirow{3}{*}{ RASS score } & \multicolumn{4}{|c|}{ Groups } & \multirow{3}{*}{$\begin{array}{c}\text { Test } \\
\text { statistic }\end{array}$} & \multirow{3}{*}{$\begin{array}{c}p- \\
\text { value }\end{array}$} \\
\hline & \multicolumn{2}{|c|}{$\begin{array}{c}\text { Group } 1 \\
\mathrm{~N}=35\end{array}$} & \multicolumn{2}{|c|}{$\begin{array}{c}\text { Group } 2 \\
\mathrm{~N}=35\end{array}$} & & \\
\hline & $\mathrm{N}$ & $\%$ & $\mathrm{~N}$ & $\%$ & & \\
\hline \multicolumn{7}{|c|}{ On admission: } \\
\hline 0 & 35 & 100 & 35 & 100 & - & - \\
\hline \multicolumn{7}{|c|}{$\begin{array}{l}\text { Onday of onset } \\
\text { of delirium: }\end{array}$} \\
\hline-1 & 12 & 34.28 & 0 & 0.0 & 10.360 & 0.035 \\
\hline-2 & 3 & 8.57 & 0 & 0.0 & & \\
\hline 0 & 9 & 25.71 & 27 & 77.14 & & \\
\hline+1 & 7 & 20 & 5 & 14.3 & & \\
\hline+2 & 3 & 8.57 & 3 & 8.57 & & \\
\hline+3 & 1 & 2.9 & 0 & 0.0 & & \\
\hline \multicolumn{7}{|c|}{ On discharge $\mathbf{a}$ : } \\
\hline 0 & 33 & 100.0 & 33 & 100.0 & - & - \\
\hline
\end{tabular}

a: Missing 4 patients who were died.

Frequent assessment of both groups at $12 \mathrm{hrs}$ interval for the onset of delirium by using CAMICU score revealed significantly lower incidence of delirium in group II $(17.1 \%)$ than in group I (40\%), $p=0.034$. Further, all survived patients in both groups showed negative CAM score at the time of discharge (Table 5).

Table (5): Assessment of CAM score in the studied groups.

\begin{tabular}{|c|c|c|c|c|c|c|}
\hline \multirow{3}{*}{ CAM score } & \multicolumn{4}{|c|}{ Groups } & \multirow{3}{*}{$\begin{array}{c}\text { Test } \\
\text { statistic }\end{array}$} & \multirow{3}{*}{$\begin{array}{c}p- \\
\text { value }\end{array}$} \\
\hline & \multicolumn{2}{|c|}{$\begin{array}{c}\text { Group } 1 \\
\mathrm{~N}=35\end{array}$} & \multicolumn{2}{|c|}{$\begin{array}{c}\text { Group } 2 \\
\mathrm{~N}=35\end{array}$} & & \\
\hline & $\mathrm{N}$ & $\%$ & $\mathrm{~N}$ & $\%$ & & \\
\hline \multicolumn{7}{|c|}{ On admission: } \\
\hline Negative & 35 & 100.0 & 35 & 100.0 & - & - \\
\hline \multicolumn{7}{|c|}{ Onday of onset } \\
\hline \multicolumn{7}{|c|}{ of delirium: } \\
\hline Negative & 21 & 60.0 & 29 & 82.9 & 4.480 & $0.034 *$ \\
\hline Positive & 14 & 40.0 & 6 & 17.1 & & \\
\hline \multicolumn{7}{|c|}{ Ondischargea: } \\
\hline Negative & 33 & 100.0 & 33 & 100.0 & - & - \\
\hline
\end{tabular}


Monitoring the occurrence of side effects in both groups showed significantly greater incidence of extrapyramidal effects, prolonged QT and hypotension in group I $(2.9 \%, 8.6 \%, 14.3 \%$ respectively) compared to group II $(0.0 \%, 0.0 \%, 2.9 \%$ respectively) $(p=0.032)$ as illustrated in Table (6).

Table (6): The frequency of side effects in the studied groups.

\begin{tabular}{|c|c|c|c|c|c|c|}
\hline & \multicolumn{4}{|c|}{ Groups } & \multirow{3}{*}{$\begin{array}{c}\text { Test } \\
\text { statistic }\end{array}$} & \multirow{3}{*}{$\begin{array}{c}p- \\
\text { value }\end{array}$} \\
\hline & \multicolumn{2}{|c|}{$\begin{array}{c}\text { Group } 1 \\
\mathrm{~N}=35\end{array}$} & \multicolumn{2}{|c|}{$\begin{array}{c}\text { Group } 2 \\
\mathrm{~N}=35 \\
\end{array}$} & & \\
\hline & $\mathrm{N}$ & $\%$ & $\mathrm{~N}$ & $\%$ & & \\
\hline \multicolumn{7}{|l|}{ Side effects: } \\
\hline Extrapyramidal & 1 & 2.9 & 0 & 0.0 & 7.088 & $0.032 *$ \\
\hline Prolonged QT & 3 & 8.6 & 0 & 0.0 & & \\
\hline Hypotension & 5 & 14.3 & 1 & 2.9 & & \\
\hline No side effect & 26 & 74.3 & 34 & 97.1 & & \\
\hline
\end{tabular}

Analysis of the final outcomes of patients revealed no significant difference with regard to allcause mortality between the two groups $(p>0.999)$ (Table 7).

Table (7): The final outcome of the studied groups.

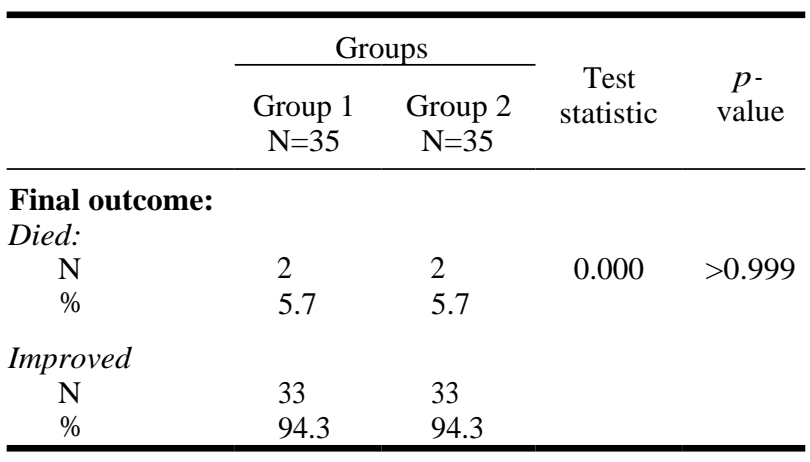

\section{Discussion}

Currently, the use of antipsychotics as part of comprehensive delirium management is safe and effective in relieving symptoms in patients with delirium [8]. However, studies have shown that once delirium started to develop, pharmacologic interventions are discreetly effective, and may even lead to longer duration and severity of delirium. Therefore, strategies to prevent delirium have been put in consideration [9]. The use of prophylactic antipsychotics has also been gaining interest. When antipsychotics drugs introduced prophylactically, their effects might be more beneficial [10].

To date, there is a lack of sufficient data on pharmacological prophylaxis using antipsychotic drugs for delirium in critically ill ICU patients. Therefore, the aim of present study was to compare the efficacy and safety of quetiapine in prophylaxis against ICU delirium in high-risk patient with that of haloperidol.

There are numerous risk factors that favor the development of delirium in ICU patients. These include the presence of comorbidities, suboptimal pain control, acid-base and water-electrolyte balance disorders, deprivation of sleep, severe infections, and chronic psychiatric disorders such as depression, dementia, cognitive deficits, all states of impaired cerebral flow and hypoxia, as well as intoxications that interfere with the metabolism of neurotransmitters [11]. These were considered in this study where patients with history of neurologic or psychiatric disorders, or drug or alcohol toxicity were excluded. Furthermore, in the present study, there were homogenous distribution of comorbidities, clinical data including the means of SBP, DBP, MAP, HR, RR, and temperature as well as most of the laboratory data between both groups.

Despite random allocation of the studied patients to group I and group II, comparison of baseline laboratory data revealed significantly higher median creatinine in group I 1.3 (.9-1.9) than group II 1.0 (.8-1.4). Likewise, the mean PH (7.38 \pm .05 vs $7.40 \pm .04)$ and $\mathrm{HCO} 3(23.2 \pm 4.1$ vs $26.3 \pm 3.4)$ were significantly lower in group I than group II.

As regard APACHE II score, mean APACHE II score on admission and on discharge was significantly higher in group I ( $21 \pm 4.3)$ than group II (18.1 \pm 5.2$)$, group I $(12.9 \pm 3.3)$ than group II $(9.7 \pm$ 2.6).

Severity of illness increased and this shared in higher incidence of occurrence of delirium in group 1 than group 2 in our present study.

In agreement with our study, previous studies observed that the incidence of postoperative delirium was higher in patients with endotracheal intubation on ICU admission than in those without ( $28.8 \%$ vs $15.1 \%)$. This may be due to a more severe underlying condition in intubated patients on ICU admission (APACHE II score: 10.9 \pm 4.0 vs 9.8 \pm 2.9 ), which is associated with increased risk of postoperative delirium [12].

$\mathrm{Xian} \mathrm{Su}$, et al., reported in a randamized, double blind, placebo controlled trial permitted the use of supplemental sedative and/or analgesics in mechanically ventilated patients during ICU stay; consequently more of these patients received supplemental propofol (91.1\% vs $2.8 \%)$, midazolam (10.2\% vs $6.0 \%$ ) and morphine (41.9\% vs $12.9 \%$ ), each of which may increase the risk of postoperative delirium [13]. 
Boogaard reported different results from our study, in a randomized controlled trial of Haloperidol prophylaxis in critically ill patients with a high risk for delirium, that the intervention group patients tended to have a slightly lower APACHE-II score than control group (borderline significant difference between the two groups) (19 \pm 6 vs 20 \pm 7 ) [5] .

As regard RASS score, in the present study, frequent assessment of RASS score revealed non significant differences between the studied groups on day of admission and discharge.

But, there were significant differences between the studied groups as regards the frequency of different grades of agitation or sedation as assessed by RASS score on the day of onset of delirium $(p=0.035)$.

In agreement with our study, Xian $\mathrm{Su}$, reported in randomized double blind placebo controlled trial study that the RASS scores at the end of study drug infusion were similar between two studied groups, indicating that low dose dexmedetomedine did not produce significant sedation as loading dose of dexmedetomedine was not administered and a sub-sedative infusion rate $(0.1 \mathrm{mic} / \mathrm{kg}$ per hour) was delivered [14].

In the present study, the regular assessment of the studied patients with RASS, CAM-ICU score revealed a significantly lower incidence of delirium with quetiapine $(17.1 \%)$ than with haloperidol (40\%) administration. Thus, quetiapine was more effective than haloperidol as prophylaxis for delirium in high risk critically ill patients.

Previous studies that specifically compare the efficacy of quetiapine to haloperidol in preventing delirium are few and explored inconsistent results.

In agreement with our finding, Pae et al., [15] in four open-label clinical trials using quetiapine at 25 to $200 \mathrm{mg}$ per day dosages demonstrated the effectiveness of quetiapine in almost all patients after about seven days of treatment.

These trials are limited by small sample size of 22 patients and lack of randomization.

Against our study, as we used RASS and CAMICU scores for assessment, using the delirium rating scale-revised-severity 98 (DRS-R-98) and clinical global impression scale-severity (CGI-S) scores, which were assessed at the time of pre and post-treatment. The DRS-R-98 and CGI-S scores were significantly reduced by $57.3 \%$ and $55.1 \%$, respectively.
Another point of agreement between the two studies is developing Extrapyramidal symptoms (EPS) leading to discontinuation of haloperidol. On other side; none of the patients on Quetiapine group developed EPS in both study [15,16]

Maneeton et al., reported in another double blind randomized clinical trial that equal efficacy of quetiapine and haloperidol administered orally at a flexible dose of quetiapine $(25-100 \mathrm{mg} /$ day $)$ or haloperidol (0.5-2.0mg/day) before bed time and as needed for the control of delirious behavior of critically ill patients [17].

The observed differences might be attributed to the different dosages and regimens of quetiapine and haloperidol from our study.

Girard et al., [18] reported in a prospective study in mechanically ventilated Medical and surgical ICU patients (sample size 105 patients divided into 35 Haloperidol, 35 Quetiapine and 35 placebo) CAM-ICU used for screening to demonstrate the feasibility of a placebo-controlled trial of antipsychotics for delirium in the ICU and test the hypothesis that antipsychotics would improve days alive without delirium or coma, duration of delirium, ICU and hospital length of stay, no difference in the duration of delirium among study groups.

The point of diffidence of the present study is being usage of Quetiapine is superior as a prophylaxis of ICU delirium regarding the incidence of delirium, and safety [18].

Santos et al., [19] systematic review Studies investigated the prophylactic use of haloperidol against placebo in critically ill patients with a high risk of delirium revealed conflicting results. Significant differences were found between participants, interventions, outcome measures (clinical heterogeneity) and designs (methodological heterogeneity). Five studies met inclusion criteria, one of these studies was excluded due to poor methodological quality. The remaining four original studies (total of 1142 patients) were included in the review. Three studies were randomized controlled trials and one was a cohort study. Two studies confirmed the effectiveness of haloperidol prophylaxis in critically ill patients with high risk of delirium. These studies showed that short term prophylactic administration of low-dose intravenous haloperidol significantly decreased the incidence of delirium in elderly patients admitted to intensive care units after non cardiac surgery and in general intensive care unit patients with high risk of delirium. 
However, the two remaining studies showed contradictory results in mechanically ventilated critically ill adults, revealing the administration of haloperidol reduced delirium prevalence, delayed its occurance, and/or shorten its duration [19].

Wang et al., [20] reported that Short-term administration of low-dose intravenous haloperidol at $0.5 \mathrm{mg}$ intravenous bolus injection followed by continuous infusion at a rate of $0.1 \mathrm{mg} / \mathrm{h}$ for $12 \mathrm{hrs}$ significantly decreased the incidence of delirium in elderly patients who underwent non cardiac surgery during the first 7 days after surgery $15.3 \%$ $(53 / 229)$ in the haloperidol group and $23.2 \%$ $(53 / 228)$ in the control group $(p=0.031)$. The mean time to onset of delirium and the mean number of delirium-free days were significantly longer (6.2 days [95\% confidence interval 5.9-6.4] vs.5.7 days [95\% confidence interval 5.4-6.0]; $p=0.021$ and $6.8 \pm 0.5$ days vs. $6.7 \pm 0.8$ days; $p=.027$, respectively), whereas the median length of ICU stay was significantly shorter $(21.3 \mathrm{hrs}$ [95\% confidence interval 20.3-22.2] vs. $23.0 \mathrm{hrs}$ [95\% confidence interval 20.9-25.1]; $p=.024$ ) in the haloperidol group than in the control group.

There was no significant difference with regard to all cause 28-day mortality between the two groups $(0.9 \%$ [2/229] vs. $2.6 \%$ [6/228]; $p=.175)$. No drug-related side effects were documented (Wang et al., 2012). The same concept was detected by our study, lower incidence of delirium in ICU and delirium was assessed using the confusion assessment method for the intensive care unit. The point of diffidence from the present study is different route of administration of haloperidol, sample size and this study was conducted in surgical ICU.

Other studies revealed that the prophylactic administration of haloperidol at the early stage of delirium significantly reduced the incidence of severe postoperative delirium in elderly patients $[21,22]$

As well, haloperidol prophylaxis reduced the incidence of delirium exclusively in postoperative patients admitted to ICU [23]

On the other hand, the preventive administration of low-dose haloperidol did not significantly decrease the incidence or severity of postoperative delirium or shorten its persistence [24]

Furthermore Schrijver et al., [21] a multi-center, randomized, double-blind, placebo-controlled trial revealed no significant positive effect of oral haloperidol prophylaxis on delirium incidence in at risk acutely admitted older patients to hospitals with either medical or surgical conditions [21]. It seems that these conflicting results are due to heterogenous study population, sample size, drugs dosages and the frequency of their administration, besides the time of their administration whether at earlier stage of delirium onset or not.

Concerning safety of the studied drugs, monitoring the occurrence of side effects in both groups in our study showed significantly greater incidence of extrapyramidal effects, prolonged QT and hypotension with haloperidol administration $(2.9 \%$, $8.6 \%, 14.3 \%$ respectively) compared to group II $(0.0 \%, 0.0 \%, 2.9 \%$ respectively) $(p=0.032)$.

However, analysis of the final outcomes of patients revealed no significant difference with regard to all-cause mortality between the two groups $(p>0.999)$.

In agreement with these findings, Hale et al., [25] a prospective observational study of the ICU patients with delirium who received antipsychotics drugs reported corrected QT interval (QTc) prolongation $(10 \%)$, drowsiness $(20 \%)$, ventricular tachycardia (10\%), fever (10\%), and neutropenia (10\%) as adverse drug reactions. Adverse effects were mainly observed in patients receiving the firstgeneration antipsychotic drugs as Haloperidol.

As well Devlin et al., [26] reported, the use of quetiapine $(50 \mathrm{mg}$ orally every 12 hours which was increased every 24 hours up to $200 \mathrm{mg}$ every 12 hours did not produce significant differences in the incidence of QTc prolongation or extrapyramidal symptoms in comparison with placebo.

Nikooie et al., [27] also reported in a more recent systematic review of Randamised Controlled Trials of different antipsychotics drugs against placebo, a lower incidence of adverse drug effects with quetiapine.

The high incidence of extrapyramidal symptoms with the first-generation antipsychotics resulting from their powerful inhibition of D2 receptors. Further, these extrapyramidal symptoms mostly occur with administration of high dosages of these drugs. They include akathisia, acute dystonic reaction, parkinsonism, and tardive dyskinesia [28].

It has been found that a daily dose of $5-15 \mathrm{mg}$ of haloperidol may cause extrapyramidal symptoms in $19 \%-29 \%$ patients with delirium, which is greater than the incidence in those taking atypical antipsychotics. However, a fixed low dose of oral ha- 
loperidol $1 \mathrm{mg}$ twice per day did not result in significant QTc prolongation even in acutely hospitalized adults with multiple comorbidities [29]

Nevertheless, Shen reported in a systematic review and meta-Analysis of haloperidol effects in adult delirious patients against placebo revealed absence of differences regarding QTc interval prolongation, extrapyramidal symptoms, or mortality [30].

The limitations of this study include the fact that a small number of studies met inclusion criteria, hence the sample size was relatively small. Further limitations were the heterogenesity of the included studies, the fact that other medications such as dexmedetomidine were reported to have aided in reduction of postoperative delirium, and the lack of placebo group for comparison of haloperidol with second generation antipsychoyics for delirium treatment.

Furthermore, Burbuqe reported in a cohort study and review of the literature that low-dose intravenous haloperidol administration in patients admitted in the cardio-surgical intensive care unit was safe and did not produce a newly onset long QT syndrome or adverse outcomes ( $r=0.144$, $p=0.23)[31]$.

All-cause mortality outcome was comparable in both groups in our study. This coincides with a study that compared the risk of developing a serious adverse event that require acute care hospital admission or death in patients receiving either typical antipsychotics or atypical antipsychotics against placebo. They detected 2.4 times risk for patients on typical antipsychotics compared to 1.9 times for patients on atypical antipsychotics than placebo [32]. Additionally, a network meta-analysis of RCTs that investigated various pharmacological agents used for the prevention of delirium reported that all-cause mortality was non significantly higher compared to placebo or control groups during delirium prevention [33].

\section{Conclusion:}

Quetiapine was more effective than haloperidol in the prophylaxis of delirium in high risk patients admitted in the ICU. Additionally, quetiapine was safer and more tolerable than haloperidol regarding the lower incidence of extrapyramidal symptoms, prolonged QTc interval, and hypotension. Both drugs were comparable regarding all-cause mortality outcomes.

\section{References}

1- APA: Diagnostic and statistical manual of mental disorders, fifth edition. 5 th ed. Washington, D.C.: American Psychiatric Association (APA), 2013.

2- SALLUH J.I., WANG H., SCHNEIDER E.B., et al.: Outcome of delirium in critically ill patients: Systematic review and meta-analysis. BMJ, 350: h2538, 2015.

3- OUIMET S., KAVANAGH B.P., EVANS D.A., et al.: Incidence, risk factors and consequences of ICU delirium. Intensive Care Med., 33: 66-73, 2007.

4- MISTRALETTI G., PELOSI P., MANTOVANI E.S., BERARDINO M. and GREGORETTI C.: Delirium: Clinical approach and prevention. Best Pract Res. Clin. Anaesthesiol., 26 (3): 311-26, 2012.

5- MILBRANDT E.B., KERSTEN A., MARGOLIN R., et al.: Haloperidol use is associated with lower hospital mortality in mechanically ventilated patients. Crit Care Med., 33: 226-9, 2005.

6- MAZE M., SCARFINI C. and CAVALIERE F.: New agents for sedation in the intensive care unit. Crit Care Clin., 17: 881-97, 2001.

7- KASLIWAL M.R., McKENZIE C. and BARRETT N.A.: Quetiapine in prolonged ICU delirium. Crit Care, 14: P497, 2010.

8- MAEDA I., OGAWA A., YOSHIUCHI K., AKECHI T., MORITA T., OYAMADA S., et al.: Safety and effectiveness of antipsychotic medication for delirium in patients with advanced cancer: A large-scale multicenter prospective observational study in real-world palliative care settings. Gen. Hosp. Psychiatry, 67: 35-41, 2020.

9- GROVER S. and AVASTHI A.: Clinical Practice Guidelines for Management of Delirium in Elderly. Indian Journal of Psychiatry, 60 (Suppl 3): 329-40, 2018.

10- FOK M.C., SEPEHRY A.A., FRISCH L., SZTRAMKO R., BORGER van der BURG B.L., VOCHTELOO A.J., et al.: Do antipsychotics prevent postoperative delirium? A systematic review and meta-analysis. Int. J. Geriatr. Psychiatry, 30 (4): 333-44, 2015.

11- TILOUCHE N., HASSEN M.F., ALI H.B.S., JAOUED O., GHARBI R. and EL ATROUS S.S.: Delirium in the Intensive Care Unit: Incidence, Risk Factors, and Impact on Outcome. Indian journal of critical care medicine: Peer-reviewed, official publication of Indian Society of Critical Care Medicine, 22 (3): 144-9, 2018.

12- BURKHART C.S., DELL-KUSTER S., GAMBERINI M., et al.: Modifiable and non modifiable risk factors for postoperative delirium after cardiac surgery with cardiopulmonary bypass. J. Cardiothoracic Vasc. Anesth., 24 (4): 555-9, 2010.

13- SANDERS R.D. and MAZE M.: Contribution of sedativehypnotic agents to delirium via modulation of the sleep pathway. Can. J. Anaesth., 58 (2): 149-56, 2011.

14- PANDHARIPANDE P., COTTON B.A., SHINTANI A., et al.: Motoric subtypes of delirium in mechanically ventilated surgical and trauma intensive care unit patients. Intensive Care Med., 33: 1726-31, 2007.

15- PAE C.U., LEE S.J., LEE C.U., LEE C. and PAIK I.H.: A pilot trial of quetiapine for the treatment of patients 
with delirium. Hum. Psychopharmacol., 19 (2): 125-7, 2004.

16- MANEETON B., MANEETON N. and SRISURAPANONT M.: An open-label study of quetiapine for delirium. J. Med. Assoc. Thai., 90 (10): 2158-63, 2007.

17- MANEETON B., MANEETON N., SRISURAPANONT M. and CHITTAWATANARAT K.: Quetiapine versus haloperidol in the treatment of delirium: A double-blind, randomized, controlled trial. Drug design, development and therapy, 7: 657-67, 2013.

18- GIRARD T.D., PANDHARIPANDE P.P., CARSON S.S., SCHMIDT G.A., WRIGHT P.E., CANONICO A.E., et al.: Feasibility, efficacy, and safety of antipsychotics for intensive care unit delirium: The MIND randomized, placebo-controlled trial. Crit Care Med., 38: 428-37, 2010.

20- WANG W., LI H.L., WANG D.X., ZHU X., LI S.L., YAO G.Q., et al.: Haloperidol prophylaxis decreases delirium incidence in elderly patients after noncardiac surgery: A randomized controlled trial*. Crit Care Med., 40 (3): 7319, 2012.

21- SCHRIJVER E.J., de GRAAF K., de VRIES O.J., MAIER A.B. and NANAYAKKARA P.W.: Efficacy and safety of haloperidol for in-hospital delirium prevention and treatment: A systematic review of current evidence. Eur. J. Intern. Med., 27: 14-23, 2016.

22- FUKATA S., KAWABATA Y., FUJISHIRO K., KITAGAWA Y., KUROIWA K., AKIYAMA H., et al.: Haloperidol prophylaxis for preventing aggravation of postoperative delirium in elderly patients: A randomized, open-label prospective trial. Surg Today, 47 (7): 815-26, 2017.

23- LIN P., ZHANG J., SHI F. and LIANG Z.A.: Can haloperidol prophylaxis reduce the incidence of delirium in critically ill patients in intensive care units? A systematic review and meta-analysis. Heart Lung, 49 (3): 265-72, 2020.

24- FUKATA S., KAWABATA Y., FUJISIRO K., KATAGAWA Y., KUROIWA K., AKIYAMA H., et al.: Haloperidol prophylaxis does not prevent postoperative delirium in elderly patients: A randomized, open-label prospective trial. Surg Today, 44 (12): 2305-13, 2014.

25- HALE G.M., KANE-GILL S.L., GROETZINGER L. and SMITHBURGER P.L.: An Evaluation of Adverse Drug Reactions Associated With Antipsychotic Use for the Treatment of Delirium in the Intensive Care Unit. J. Pharm. Pract., 29 (4): 355-60, 2016.

26- DEVLIN J.W., ROBERTS R.J., FONG J.J., SKROBIK Y., RIKER R.R., HILL N.S., et al.: Efficacy and safety of quetiapine in critically ill patients with delirium: A prospective, multicenter, randomized, double-blind, placebo-controlled pilot study. Crit Care Med., 38 (2): 41927, 2010.

27- NIKOOIE R., NEUFELD K.J., OH E.S., WILSON L.M., ZHANG A., ROBINSON K.A., et al.: Antipsychotics for Treating Delirium in Hospitalized Adults: A Systematic Review. Ann. Intern. Med., 171 (7): 485-95, 2019.

28- REZNIK M.E. and SLOOTER A.J.C.: Delirium Management in the ICU. Curr. Treat Options Neurol., 21 (11): 59, 2019.

29- SHAFIEKHANI M., MIRJALILI M. and VAZIN A.: Psychotropic drug therapy in patients in the intensive care unit - usage, adverse effects, and drug interactions: A review. Ther. Clin. Risk Manag., 14: 1799-812, 2018.

30- SHEN Y.Z., PENG K., ZHANG J., MENG X.W. and JI F.H.: Effects of Haloperidol on Delirium in Adult Patients: A Systematic Review and Meta-Analysis. Med. Princ Pract., 27 (3): 250-9, 2018.

31- BURBUQE I., BOETTGER S., SCHUBERT M., BETTEX D. and RUDIGER A.: QTc prolongation after haloperidol administration in critically ill patients post cardiovascular surgery: A cohort study and review of the literature. Palliat Support Care, 1-13, 2020.

32- ROCHON P.A., NORMAND S.L., GOMES T., GILL S.S., ANDERSON G.M., MELO M., et al.: Antipsychotic therapy and short-term serious events in older adults with dementia. Arch. Intern. Med., 168 (10): 1090-6, 2008.

33- WURTMAN R.J., HEFTI F. and MELAMED E.: Precursor control of neurotransmitter synthesis. Pharmacol. Rev., 32: 315-35, 2000. 


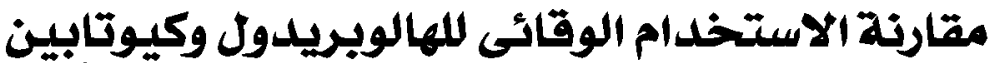

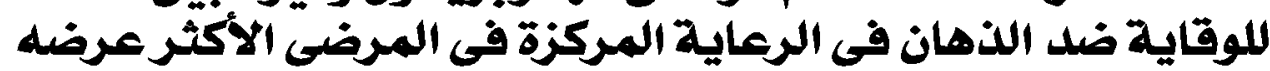

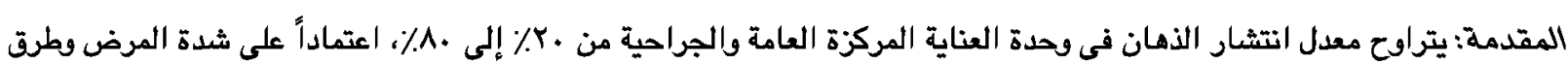
التشخيص.

الهدف من الدراسة: فحص فعالية وأمان استخدام عقار الكيوتابين في الوقاية من الذهان في المرضى الاكثر عرضة داخل وحدة العناية

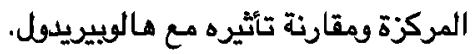

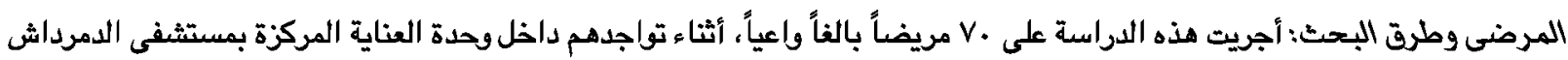

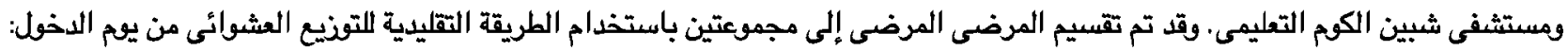

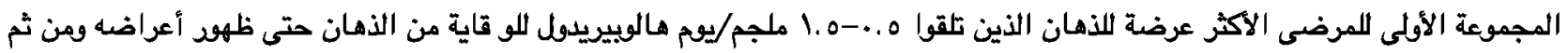

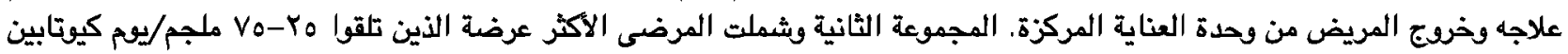
اللوقاية من الذهان حثى ظهود أعراضه ومن ثم علاجه وخروج المريض من وحدة العناية المركزة.

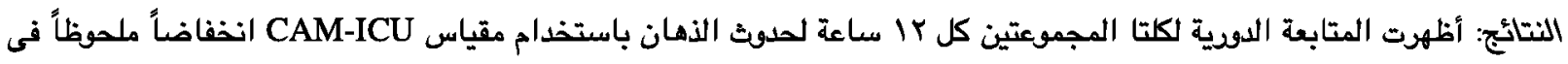

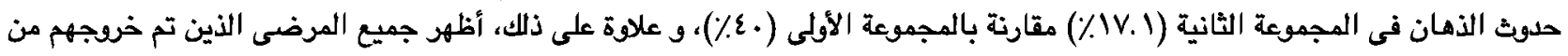

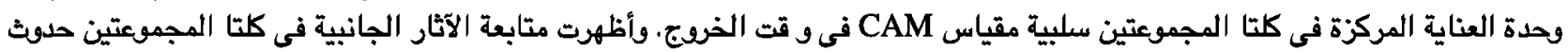

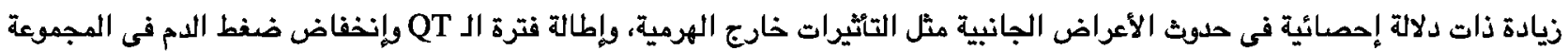

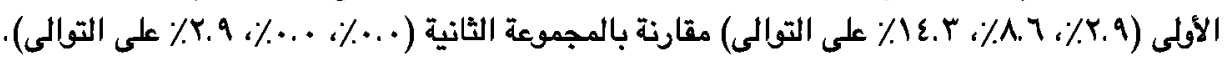

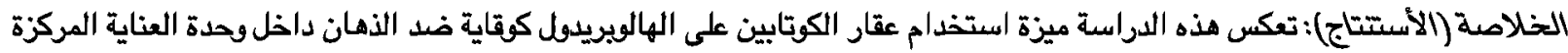

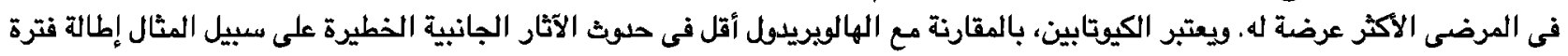

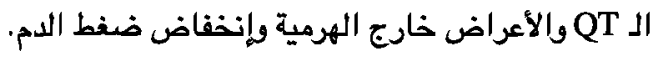

